\title{
QUADRO DOS FARSANTES NA COMÉDIE FRANÇAISE: INTERCULTURALIDADE E IDENTIDADE DE PAPÉIS NA SEGUNDA METADE DO SÉC. XVII
}

\author{
Walter Lima Torres
}

\section{Resumo}

Este artigo busca uma análise iconográfica do quadro Farceurs français et italiens ayant appartenu aux théatres royaux. A questão que a análise da obra coloca é a contradição entre atores e papéis tipos vinculados ao gênero farsa.

Palavras-chave: iconografia teatral, cultura e prática teatral, atores e tipos.
Abstract

This article proposes an iconographic analysis of the painting Farceurs français et italiens ayant appartenu aux théatres royaux. The question developped here is the contradiction between acteurs and caracters-types in the gender farce.

Keywords: dramatic iconographie, theatrical culture and pratice, actors and types.

A obra aqui examinada intitula-se Farceurs français et italiens ayant appartenu aux théatres royaux (Farsante franceses e italianos que pertenceram aos Teatros Reais). Trata-se de uma pintura que data de 1670 e que por vezes é atribuída a Vério e por outras é tida como anônima. O original encontra-se na Comédie Française em Paris.

Pode-se ler de maneira geral em algumas legendas que acompanham o quadro em livros, manuais de história do teatro ou da arte, ou ainda em sites na internet, por exemplo, que: "Este quadro, pintado em 1670, reuniu os mais célebres 'farsantes' da primeira metade do século XVII. Entre eles figura Molière como Arnolphe de A Escola de Mulheres. O original pertence a Comédie Française" (BEDIER e HAZARD, 1948, p.58). Ou ainda "Num cenário de praça pública em quatro planos iluminado por seis lustres de doze velas e uma ribalta de trinta e quatro velas, figuram dezesseis personagens cujos nomes estão escritos em letras douradas da esquerda para direita (...)" (LORCEY, 1980, p. 20).

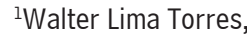
ator, diretor e professor de Estudos

Teatrais na UFPR. limatorres@ufpr.br / www.estudosteatrais. blogspot.com/ 
Em linhas gerais, descrições como as supracitadas não são mais do que uma leitura do paratexto do próprio quadro, visto que a tela trás duas inscrições textuais: a) Encimando o brasão no alto do quadro pintado com a flor de liz característica de Louis XIV, protetor da trupe, pode-se ler em francês o título: "farsantes franceses e italianos desde 60 anos atrás e mais, pintados em 1670"; b) pode-se igualmente ler na parte inferior do quadro o nome das dezesseis figuras pintadas sobre a tela. Portanto, as legendas que se perpetuam juntamente com a reprodução da obra nos diversos suportes e meios de comunicação nada mais é do que uma reiteração do que a parte paratextual presente no próprio quadro pode oferecer a quem aprecie a obra.

A hipótese que se coloca é de como ler o quadro ou problematiza-lo a partir das imagens propriamente ditas que ele retrata. Se não se é capaz de dizer mais e melhor sobre a autoria do quadro hoje, pelo menos se investigará acerca de informações que colaborem no entendimento de uma maneira de pensar a representação do teatro, do ator-cômico e de papéis cômicos na segunda metade do século XVII. Isso permitirá diagnosticar elementos de uma cultura e uma prática teatral características do período em questão que revelam uma mentalidade específica.

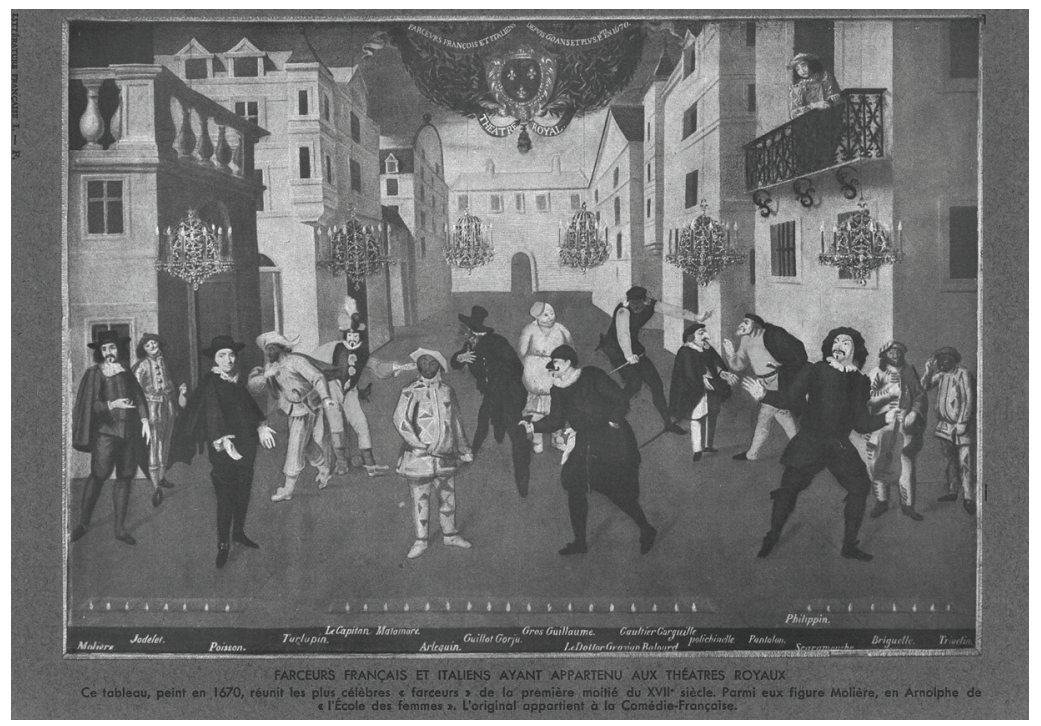

Les Farceurs Français et Italiens. Óleo sobre tela, atribuído a Verio, 1670 Coleção da Comédie Française, Paris.

O quadro é composto como já foi observado por dezesseis figuras dispostas sobre um palco, o Palco do Théâtre Royal. As dezesseis figuras incluindo aquela localizada na sacada da direita estão distribuídas em planos até a primeira metade do palco. Esta distribuição se dá sobre um cenário pintado 


\section{Urdimento}

que nos remete para um décor típico de comédias, sugerindo a praça pública já mencionada. Telões pintados sobre o palco reproduzindo casas, janelas e portas cujas linhas formam uma perspectiva à maneira Renascentista buscam o efeito de trompe l'ail. O cenário simula, a maneira de Serlio, um espaço urbano, do tipo "vista para comédia”, posto que se encontram ali casas assobradadas sem as características angulosas e verticalizantes (obeliscos, prismas, pirâmides, arcos, etc,) que caracterizariam um ambiente de tragédia. Atente-se para o destaque da figura na sacada da direita que nos confirma o ambiente das farsas bem ao gosto das cenas de Molière. Nesse gênero é clássica a cena no seu George Dandin onde Angélique se dirige da sacada ao marido Dandin depois que a porta se fecha e ele fica "preso", fora de casa. Ornam ainda esse palco seis lustres que pendem do urdimento e ao acentuarem o efeito da perspectiva sugerem a idéia de uma massa de luz total, produzida por setenta e duas velas se nos detemos na descrição acima de Lorcey. A luz do quadro, segundo o pintor não reflete, a materialidade histórica associada aos parcos recursos de iluminação. Percebe-se como única interferência dessa luz os ligeiros efeitos das sombras das pernas das figuras do primeiro grupo, que em primeiríssimo plano são projetadas nas tábuas. Sabe-se que no séc. XVII palco e platéia restavam ambos acesos durante a representação. Não haveria figuras dispostas no fundo do palco visto que não teria bastante iluminação para elas no contexto das condições materiais de representação do período.

O ponto de vista escolhido pelo pintor que revela essa perspectiva frontal tem tudo para ser de um camarote em face do palco, local privilegiado que poderia abarcar a totalidade da cena e desfrutar do efeito da perspectiva sem nenhum obstáculo para seu olhar. Pensaríamos então no camarote do príncipe.

O palco idealizado pelo pintor não revela nenhuma surpresa, salvo a ausência da caixa do ponto. Trata-se certamente de um cenário típico para “comédias" que fazem sair de casa seus personagens para no exterior, no ambiente da rua e/ou da praça dar a ver ao espectador o desenvolvimento da ação. As figuras reclamam nossa atenção, visto que a forma pela qual estão dispostas as dezesseis imagens masculinas, verifica-se uma organização do "tipo display" de propaganda em corpo inteiro ${ }^{2}$. Provavelmente, o procedimento do pintor pode ter sido o de fazer uma espécie de copiar/colar, visto que teria que compor uma figura de cada vez e não necessariamente todas as figuras ao mesmo tempo. Pode-se aventar ainda que uma vez o fundo preparado; as figuras escolhidas; essas seriam "aplicadas" na tela. O pintor teria primeiro esboçado cada figura, separadamente, para depois aplica-la na cena do palco imaginário.

Dentro desse "efeito display" seguindo o princípio do "decalcar" a figura do "Real” e aplica-la sobre o "álbum-palco" a legenda dos nomes, em douradas letras, permite ao observador reconhecer da esquerda para direita

${ }^{2}$ Estima-se 0 efeito display ao qual estamos chamando atenção aqui, que ele se refere às possíveis condições materiais de realização da pintura. Esse efeito está condicionado pelo aparente isolamento entre as figuras estabelecidas pelos seus melhores recortes para representação.

Supõe-se que seria impossível ao pintor fazer posar todos os atores ao mesmo tempo, alguns já haviam morrido quando da produção da obra. Evidentemente, não se trata de fotografia, portanto seguramente o recurso disposto foi 0 do esboço isolado, para posterior transposição à tela. Uma sorte de copiar / colar. 
as seguintes figuras em corpo inteiro: Molière; Jodelet; Poisson; Turlupin; Le Capitain Matamore; Arlequin; Guillot Gorju; Gros Guillaume; Le Dottore Grazion Balourd; Gaultier-Garguille; Polichinelle; Pantalon; Philippin (sacada); Scaramouche; Briguella; Trivellin. A escrita de todos os nomes é afrancesada na legenda.

Quem olha o quadro repara a ausência de silhuetas femininas. Essa é uma questão que foi deixada em aberto. Pois não haveria espaço para tratala aqui. Não por que este seja um assunto de menor interesse, ao contrario. Seria fundamental mapear as atrizes ligadas ao jogo cômico do período problematizando essa ausência que revela uma mentalidade que determina não só a própria ausência de tipos femininos quanto o próprio critério de seleção empregado pelo pintor, isto é, a própria seleção feita por outrem e delegada ao pintor em forma de encomenda. Essas são questões que não são especuladas neste momento.

O observador pode igualmente constatar que nenhuma das figuras está descalça, ou mal vestida. Ao contrario, todas possuem as cabeças cobertas, podendo-se deduzir que as mesmas estão caracterizadas, de alto a baixo, da forma mais completa e rigorosa com seus figurinos mais expressivos, pois cada qual está acompanhado, quando se faz necessário, de um objeto pessoal (chapéu, turbante, capa, adaga, espada, instrumento musical, bastão, saco de dinheiro, bengala, etc) que colabora na sua caracterização. Note-se que apesar do uso da máscara, as figuras assim representadas, com seus objetos de uso pessoal, estão mais personalizadas do que individualizadas.

Quanto ao emprego da máscara, vê-se que algumas figuras portam máscara ou meia-máscara e outras estão com seus rostos à mostra ou enfarinhados como Gros-Guillaume. É difícil unicamente mediante às imagens que se dispõe afirmar o numero exato de cada grupo). O olhar da platéia não é desprezado pelo pintor, visto que ele concebe figuras que olham diretamente para um espectador hipotético fora do quadro, (Arlequim, Poisson, Jodelet, Capitan). Ou seria o olhar de quem posa para quem simplesmente lhe eterniza a imagem? A pintura parece não querer retratar um momento especial, uma cena teatral fechada em si, isto é reflexo do texto de uma peça ou lembrança de uma cena vista pelo pintor, ou ainda o relato de um momento familiar ou acontecimento histórico. A cena é coletiva e a narrativa é uma imagem montada

${ }^{3}$ Comparem-se as obras de Watteau e Longhi, por exemplo. Trata-se dos principais pigmentos empregados no período para colorir os tecidos. onde se sobrepõe uma possível identidade forjada entre ficção e realidade.

Quanto às cores que sobressaem dos figurinos elas são: preto, vermelho, branco, alguns tons de azul e amarelo. Uma paleta bastante elementar que não foge às convenções de cores empregadas geralmente na reprodução desse gênero de figuras ${ }^{3}$. Além da qualidade dos tecidos há a relação entre a cor e a tipologia representada por cada figura. Seria possível associar a cor dominante 
de cada traje com o perfil comportamental do tipo que o veste? Por suposição, o preto poderia ser associado a um temperamento menos belicoso e bilioso ou violento, e sim mais sério atribuído aos mais velhos. O vermelho dominaria aqueles mais suscetíveis aos ataques coléricos Pantalon, Gaultier Gargouille. O vermelho do Matamore é temperado com um azul que não está presente em mais nenhuma figura. Jodelet se destaca trajando elegante combinação em azul claro contrastando com o saco na mão em tecido vermelho. A família de Zanni é toda ela colorida, tanto Arlequin quanto Trivelin e Briguella. O branco se faz presente somente nas golas, nos jabors característicos da época e das figuras nobres de distinção. O branco domina toda a figura de Gros Guillaume cujo rosto era coberto por uma fina camada de farinha.

Independente dessa relação até cer to ponto primária acerca da tipologia das figuras com as cores representativas de seus comportamentos, note-se que o pintor conhece o seu ofício e precisa equalizar essas figuras que são "coladas" num espaço em perspectiva com o emprego de cores. Isto é, as cores fechadas aproximam as figuras enquanto que as cores abertas e claras distanciam essas mesmas figuras. Não se pode perder de vista que há procedimentos pictóricos naturais ao oficio do pintor independente da "realidade" retratada por ele. Esses preceitos e regras da própria técnica da pintura entram em campo para minimizar possíveis hierarquias do tipo "quem vai à frente de quem", mascarando assim o próprio critério que não sabemos exatamente qual foi para disposição das figuras. Pois parece lógico que houvesse uma coerência para o pintor na disposição das figuras.

Quanto à geografia do quadro, observa-se que o personagem que delimita o meio da composição é Gros Guillaume, o qual está desenhado ao fundo. Ele divide em sete o numero de figuras tanto para direita quanto para esquerda, salvo a figura de Philippin na sacada. Sobre essa marcação podese afirmar a respeito das três últimas figuras do fundo que, Gros Guillaume ocuparia muito espaço se fosse colocado mais à frente visto que de fato era gordíssimo, e como para efeito da perspectiva a cor clara distancia, o pintor aproveita-se de sua caracterização em tons de branco, pois atuava com figurino claro e o rosto enfarinhado, para fixa-lo como um ponto central de referência; já Gualtier Garguoille que aparece tanto ao lado quanto um pouco atrás de Gros Guillaume era uma figura muito alta segundo relatos sobre sua descrição, destacando-se como o mais alto desses tipos aí apresentados; e por fim a figura do Capitain Matamore cuja caracterização acompanhada de espada, capa, turbante e penacho parece ser muito volumosa. Haveria dois critérios que desempenhariam um papel decisivo nas opções do pintor? Um por conta dos tipos físicos, suas alturas, suas proporções graças às suas caracterizações devido à cor do figurino etc. E o outro devido à notoriedade dos tipos em termos de reconhecimento acerca de suas atuações juntamente com o fato de que os dois 
atores franceses já terem desaparecido em 1670. Nesse sentido, ressalta-se que a figura de Arlequim é a única colocada na primeira fila pelo pintor em tons mais claros, o que o destaca dentre os demais tipos nessa primeira linha.

Quem olha o quadro tem seu olho atraído para esse radiante ponto quase central no qual se configura a representação de Arlequim, emoldurada por um lado, primeiro por seu parceiro de canovaccio Le Dottore Grazion Balourd depois pelo célebre Scaramouche, ambos de origem italiana. Do outro lado, Arlequim é emoldurado pelas figuras de Poisson e Molière. Tanto os dois atores franceses quanto o ator italiano estavam vivos em 1670.

Como já se disse, as figuras foram dispostas em três linhas dentro de um "efeito display". Corresponde a essa marcação os nomes, em letras douradas, na parte inferior do quadro como uma espécie de legenda de identificação sobre cada espécime — vivo ou morto — da coleção do álbum. Seguindose a relação dos nomes no quadro encontramos na primeira linha: Molière, Poisson, Arlequim, Le Dottore Grazion Balourd e Scaramouche (5 figuras). Dois atores franceses (Molière e Poisson); dois personagens da Dell'Arte (Dottore e Arlequim) e por ultimo o célebre ator italiano Scaramouche. Na segunda linha, sempre da esquerda para direita três atores franceses (Jodelet, Turlupin, Guillot Gorju), seguido de quatro papéis italianos (Polichinelle, Pantalon, Briguela e Trivelin). E na terceira destaca-se mais um papel-tipo, Le Capitan Matamore, seguido por outros três atores franceses (Gros Guillaume, Gaultier Gargouille, e na sacada Phillipin).

As atitudes, as expressões dos braços e das mãos escolhidas pelo pintor seriam reveladoras do comportamento representado por cada figura? Destaque para: as mãos, a direção dos olhares (posição das cabeças) e colocação dos pés e posição das pernas num jogo de equilíbrio e desequilíbrio, estabilidade e instabilidade das figuras, efeitos natural ao jogo cômico. Esta opção se opõe à atuação hierática mais vocalizada do que corporal do registro sério preconizada por uma verticalidade trágica acompanhada por gestos codificados e "menos espontâneos" em relação ao cômico.

Curiosamente, Arlequim o personagem a quem se associa cabriolas e lazzi corporais é o mais bem plantado, retratado com os dois pés numa quase segunda posição de dança clássica, firmemente enraizado no palco em "repouso", bem estável. Contradição? Ou impossibilidade do pintor em retratalo em ação? Essa é uma questão, isto é, sobre a natureza comportamental de cada papel-tipo e a finalidade do quadro. O quadro não quer eternizar a cabriola de Arlequim nem as gags do Capitan-Matamore, a composição não dá espaço para isso e tão pouco é reveladora de uma "situação dramática”. A cena coletiva parece eternizar uma espécie de biografia resta saber de quem? Uma biografia individual ou coletiva? 
Aos poucos se percebe que as figuras italianas decalcadas da Comedia dell'Arte estão associadas em pares que "dialogam" ou "simulam uma interpelação". Arlequim e Dottore; Briguella e Trivelin; Polichinelle e Pantalon, a exceção do Capitain que conta suas bravatas diretamente ao auditório. As demais figuras da maneira como estão dispostas parecem se ignorar mutuamente. Em certa medida a cena "retratada" pelo pintor é muda do ponto de vista de uma narrativa dramática. Esta possível incomunicabilidade entre as figuras restantes se deveria a que? A primeira hipótese seria no sentido de que os papéis da Comedia dell'Arte sobreviriam graças ao jogo, estando apoiados na relação que se estabelece na ação que plasma sobre uma situação de comicidade. Incluindo-se Scaramouche, os tipos franceses - Molière; Jodelet; Poisson; Turlupin; Guillot Gorju; Gaultier-Garguille, a exceção de Gros Guillaume -, estão todos em atitudes que nos remetem a uma possível situação de jogo, mais precisamente de enunciação da palavra que possa acompanhar essa atitude ou dela advir. Porém, essa enunciação da palavra não se dirige a nenhuma outra figura, ela se dirigiria por assim dizer para fora do quadro. Ao publico imaginário? Ao pintor? Ao rei?

Se a sobrevivência do jogo da Dell'Arte se dá, como se sabe, na ação e reação; na máscara e na contra-mascara; na execução do lazzi corporal ou oral, a ênfase na atuação dos papéis franceses parece repousar no verbo, na elocução, na palavra proferida, na situação que é externalizada in verbum. Os papéis-tipos franceses que acabaram se tornando personagens de peças escritas por diferentes autores são constituídos na e pela palavra poética. Ao passo que os papéis-tipos da Dell'Arte são esculpidos em gestos, efêmeras atitudes expressas pelo jogo da pantomima e de um verbo sempre improvisado e sempre provisório, à espera de Carlo Goldoni no séc XVIII. Advém daí o fato de que os nomes relacionados no quadro referentes aos tipos franceses são na verdade pseudônimos dos atores, ao passo que do lado italiano temos somente o nome dos papéis-tipos, a exceção de Scaramouche.

Molière é Jean-Baptiste du Poquelin (1622-1673), autor de comédias dos mais famosos. Para eterniza-lo no quadro o pintor escolheu sua figura como ator e não como autor. Jodelet é Julien Bedeau (1590-1660). Ele ingressou na trupe de Molière em 1659. O nome Jodelet é consagrado pelo trabalho do ator e passa a designar diversos papéis em peças de Scarron, Thomas Corneille e até mesmo de Molière. Poisson é Raymond (1633-1690) autor e ator criador do tipo-cômico Crispin. Turlupin é Henri Legrand (1587-1637) quando representava farsas, pois quando atuava nas tragédias empregava o pseudônimo de Belleville. Já Gros Guillaume é Robert Guérin (? - 1664) para atuar nas farsas, enquanto que para subir ao palco nas tragédias empregava o nome de La Fleur. Gaultier Garguille é Hugues Guéru (1573-1634) na farsa, pois na tragédia se apresentava sob a alcunha de Fléchelles. Bertrand Hardouin de St. Jacques 


\section{Urdimento}

${ }^{4}$ Para localização das verdadeiras identidades referente aos atores recorremos a (CORVIN, 1991).
(1600-1648) é Guillot Gorju, excelente no desempenho de papéis de doutores pedantes. E Claude Deschamps de Villiers (1600-1681) é o verdadeiro nome de Philippin, o ator e autor que da sacada contempla o conjunto. A exceção de Tibério Fiorillo (1608-1694) o Scaramouche $e^{4}$ no time italiano sobressaem, unicamente, os tipos ou papéis da Dell'Arte e não os atores seus criadores. Contradição de uma relação intercultural turbulenta visto que a identidade do cômico francês parasitou a matriz italiana da Comedia dell'Arte.

Ao empregar o efeito de trompe l'ceil para organização do seu quadro em planos, o pintor não se quer ilusionista do ponto de vista do seu objeto retratado - o conjunto de atores e papéis - , apesar de fazer apelo à perspectiva, esta é só uma moldura para "cena muda” do ponto de vista de uma narrativa teatral. Teria o pintor assistido alguma vez esses atores? Como teria procedido com a representação daqueles que já haviam morrido? Certamente de memória se já os tivesse assistido ou por uma fonte iconográfica remanescente que lhe serviria de referencia. A pintura teria por fim eternizar a memória desses atores ou desses papéis ficcionais? Ou as duas coisas ao mesmo tempo? Viu-se o caráter coletivo da composição que se apresenta como um álbum à maneira de como serão mais tarde no século XIX os panoramas. Esta visão horizontal ou panorâmica das dezesseis figuras se opõe aos retratos individuais de autores e atores célebres do período em questão que foram grandes trágicos ou tiveram sua produção associada ao registro sério. Nesse sentido, sejam papéis ficcionais ou os próprios atores que as animavam, estes estão aí classificados nesse documento biográfico ou genealógico visual. Graças ao artificialismo da composição e a independência de cada figura, por conta do "efeito display", seria como se esse conjunto figurasse também, à maneira de uma galeria de papéis-tipos que compõem uma coleção. A coleção dos mais célebres farsantes que entreteram a corte de Luis XIV no século XVI.

\section{Referências bibliográficas}

CORVIN, Michel: (sous la direction de), Dictionnaire encyclopédique du théâtre. Paris: Bordas, 1991.

BEDIER, Joseph; HAZARD, Paul (sous la direction de): Littérature Française. T. I. Paris: Librairie Larrouse, 1948.

LORCEY, Jacques. La Comédie Française. Paris: Editions Fernand Nathan, 1980. PANOFSKY, Erwin. Significado nas artes visuais. São Paulo: Perspectiva, 1976. 


\section{NORMAS PARA PUBLICAÇÃO DE ARTIGOS}

A Revista Urdimento é uma publicação do Programa de PósGraduação em Teatro da Universidade do Estado de Santa Catarina e reúne artigos que contribuiem para a pesquisa na área das artes cênicas.

A Urdimento recebe as colaborações em fluxo contínuo que são analisadas pelo Conselho Editorial. As seguintes normas técnicas devem ser observadas para a publicação das contribuições.

1) Os artigos devem ter no mínimo 8 e máximo 12 laudas. Resenhas de livros entre 3 e 4 laudas. Os textos deverão ser digitados com letra Times New Roman, tamanho 12, com espaçamento $1,5 \mathrm{~cm}$ em Word para Windows (ou compatível).

2) Os colaboradores devem incluir dados especificando as atividades que exercem, a instituição (se for o caso) em que trabalham e dados básicos dos respectivos currículos.

3) Solicita-se clareza e objetividade nos títulos.

4) Os artigos devem vir acompanhados de resumo com no máximo de 6 linhas e 3 palavras-chaves, ambos com as respectivas traduções para o inglês.

5) O envio do artigo original implica na autorização para publicação, tanto na forma imprensa como digital da revista.

6) Notas explicativas serão aceitas desde que sejam imprescindíveis e breves. As citações no corpo do texto que sejam superiores a 5 linhas devem ser digitadas em espaço simples com tamanho 10 em itálico. As citações no corpo do texto devem seguir a formatação (AUTOR, 2008, p.1).

7) Todas as palavras em língua estrangeira devem estar em itálico.

8) As notas de rodapé devem ser apresentadas no fim de cada página e numeradas em algarismos arábicos.

9) Caso os artigos incluam fotos, desenhos ou materiais gráficos 
da autoria de terceiros, é indispensável carta de autorização. O material deverá vir acompanho de legendas de identificação. O material gráfico deve ser reduzido ao mínimo indispensável, em formato JPG e com resolução de 300 dpi, enviadas em arquivos separados do texto. Somente serão publicadas imagens em preto e branco.

10) O material para a publicação deverá ser encaminhado em duas vias impressas e uma em formato digital (programa word) para o e-mail urdimento@udesc.br aos cuidados da revista.

Endereço para correspondência e envio de colaborações:

\section{Revista Urdimento}

Programa de Pós-Graduação em Teatro - UDESC

Av. Madre Benvenuta, 1.907 - Itacorubi

88.035-001 - Florianópolis - SC

E-mail: urdimento@udesc.br

\section{Normas para citação de referência bibliográfica:}

\section{Livros}

SOBRENOME, Prenomes do autor. Título: subtítulo. edição. Local: editor, ano de publicação.

\section{Teses/ Dissertações/Monografias}

SOBRENOME, Prenomes do autor. Título: subtítulo. ano. $\mathrm{n}^{\circ}$ total de páginas. Tese, Dissertação ou Monografia (grau e área) - Unidade de Ensino, Instituição, Local e ano.

\section{Artigos de periódicos na internet}

SOBRENOME, Prenomes do autor. Título do artigo. Título da Revista, local, volume, número, páginas do artigo, mês e ano de publicação. Notas. Disponível em: <http://www....> Acesso em: dia mês (abreviado) ano, hora: minutos.

\section{Artigos}

SOBRENOME, Prenomes do autor do artigo. Título do artigo. Título da Revista, local, volume, número, páginas do artigo (inicial e final), mês e ano da publicação do artigo. 
Realização:

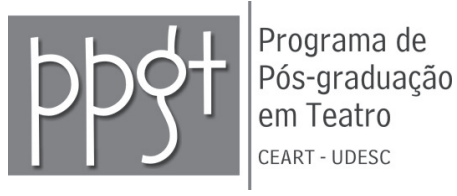

Programa de Pós-Graduação em Teatro



Centro de Artes 
Este projeto editorial foi criado eletronicamente utilizando o software Adobe In Design CS3. As famílias tipográficas Bell MT e BellCent são utilizadas em toda esta revista. 